\title{
METODE DEMONSTRASI SADARI TERHADAP KEMAMPUAN MELAKUKAN SADARI PADA WANITA USIA SUBUR
}

\author{
Lini Hastuti ${ }^{1}$, Rachmawaty M. Noer ${ }^{2}$, Mira Agusthia ${ }^{3}$ \\ Program Studi Ilmu Keperawatan,STIKes Awal Bros Batam \\ linihastutiaz@gmail.com, rachmawatymnoer1977@gmail.com²
}

\begin{abstract}
Breast cancer has the highest prevalence in Indonesia, affecting women aged 20-40 years. This shows that the low ability of women of childbearing age in doing BSE in order to avoid breast cancer. One way to prevent breast cancer is to do breast self-examination (BSE) which can be done personally to find out the symptoms of breast cancer. This study aims to determine the effect of health education with demonstration methods on the ability of women of childbearing age to perform breast selfexamination (BSE) in an effort to detect breast cancer early. The method used in this study is a preexperimental design with the type used is the One Group Pretest Postest. The sampling technique in this study used purposive sampling with a sample size of 26 people. The instrument used was a questionnaire. Data analysis using willcoxon match paired test. This research shows that before being given health education with demonstrations of women of childbearing age in Resun Village, North Lingga District, $62.9 \%$ still have sufficient ability to do BSE. After being given health education with treatment in the form of demonstrations, women of childbearing age have a good ability in doing BSE, namely $80.8 \%$. From the results of the ability statistical test before and after health education, the value of $p=0.000$ ( $p<0.05)$ was obtained. There is an effect of implementing breast selfexamination (BSE) on increasing the ability of women of childbearing age to detect breast cancer. It is hoped that every health agency will always conduct socialization about health to women and collaborate with health workers, especially regarding BSE checks.
\end{abstract}

Keywords: Health Education, Ability, BSE, WUS

\begin{abstract}
ABSTRAK
Kanker payudara memiliki prevalensi tertinggi di Indonesia yang menyerang para perempuan yang berkisar usia 20-40 tahun. Hal ini menunjukkan bahwa masih rendahnya kemampuan wanita usia subur dalam melakukan SADARI agar terhindar dari kanker payudara. Salah satu cara untuk mencegah kanker payudara adalah dengan melakukan pemeriksaan payudara sendiri (SADARI) yang bisa dilakukan secara pribadi agar mengetahui gejala- gejala kanker payudara. Penelitian ini bertujuan untuk mengetahui pengaruh pendidikan kesehatan dengan metode demonstrasi terhadap kemampuan wanita usia subur dalam melakukan pemeriksaan payudara sendiri (SADARI) dalam upaya deteksi dini kanker payudara. Metode yang digunakan pada penelitian ini adalah penelitian pre experiment design dengan jenis yang digunakan adalah One Group Pretest Postest. Teknik pengambilan sampel dalam penelitian ini menggunakan Purposive Sampling dengan jumlah sampel 26 orang. Instrumen yang digunakan adalah kuesioner. Analisa data menggunakan uji willcoxon match paired test. Penelitian ini menujukkan bahwa sebelum diberikan pendidikan kesehatan dengan demonstrasi wanita usia subur di Desa Resun Kecamatan Lingga Utara masih memiliki kemampuan cukup 62,9\% dalam melakukan SADARI. Setelah diberikan pendidikan kesehatan dengan perlakuan berupa demonstrasi wanita usia subur memiliki kemampuan baik dalam melakukan SADARI yaitu 80,8\%. Dari hasil uji statistik kemampuan sebelum dan setelah pendidikan kesehatan diperoleh nilai $p=0.000(p<0.05)$. Ada pengaruh pelaksanaan pemeriksaan payudara sendiri (SADARI) terhadap peningkatan kemampuan wanita usia subur dalam upaya deteksi dari kanker payudara. Diharapkan agar setiap instansi kesehatan selalu melakukan sosialisasi tentang kesehatan pada wanita dan bekerjasama dengan petugas kesehatan terutama tentang pemeriksaan SADARI.
\end{abstract}

Kata Kunci : Pendidikan Kesehatan, Kemampuan, SADARI, WUS 


\section{PENDAHULUAN}

\section{World Health Organization} (WHO), menuturkan bahwa terdapat lima besar penyakit kanker di dunia diantaranya yaitu kanker payudara, kanker paru- paru, kanker hati, kanker usus besar, dan kanker lambung. WHO mengestimasikan bahwa sekitar 84 juta orang di dunia meninggal akibat kanker dalam rentang waktu 2005-2015. Survei yang dilakukan organisasi kesehatan dunia manyampaikan bahwa 8-9 persen perempuan mengalami kanker payudara. Hal itu membuat kanker payudara sebagai jenis kanker yang paling banyak ditemui pada wanita setelah kanker leher rahim .

Indonesia memiliki angka kanker payudara mencapai 42,1 orang per 100.000 penduduk dengan rata-rata kematian akibat kanker mencapai 17 orang per 100 ribu penduduk (KEMENKES).Dan terdapat peningkatan jumlah kasus kanker yaitu 1,4 per 100 ribu penduduk di tahun 2013 menjadi 1,79 per 100 ribu penduduk pada tahun 2018 (Riskesdas, 2018). Data tersebut diperkuat lagi dengan hasil riset menteri kesehatan Republik Indonesia bahwa data Globocan menyebutkan di tahun 2018 terdapat 18,1 juta kasus baru dengan angka kematian sebesar 9,6 juta kematian, dimana 1 dari 5 laki-laki dan 1 dari 6 perempuan di dunia mengalami kejadian kanker.

Berdasarkan angka kejadian penyakit kanker di Indonesia (136.2/100.000 penduduk) berada pada urutan 8 di Asia Tenggara, sedangkan di Asia urutan ke 23. Angka kejadian untuk perempuan yang tertinggi adalah kanker payudara yaitu sebesar 42,1 per 100.000 penduduk dengan rata-rata kematian 17 per 100.000 penduduk yang diikuti kanker leher rahim sebesar 23,4 per 100.000 penduduk dengan ratarata kematian 13,9 per 100.000 penduduk
(KEMENKES, 2019). Polemik bagi perempuan Indonesia yang merupakan objek dari terserangnya penyakit kanker payudara. Maka dengan beberapa faktor penyebab dan data hasil penelitian tentang kanker payudara sudah sewajarnya jika perempuan Indonesia mengetahui SADARI kanker payudara diusia dini. Kasus kanker payudara menurut laporan penyakit tidak menular pada tahun 2017 di Kabupaten Lingga dengan jumlah kasus kanker payudara sebanyak 31 orang dan diantaranya 7 kasus di puskesmas pancur kecamatan Lingga Utara dan 3 kasus di desa yang akan saya teliti yaitu Desa Resun.

Berdasarkan penelitian yang dilakukan oleh (Dyanti, 2016)didapatkan hasil penelitian menunjukkan terdapat enam faktor yang memiliki hubungan bermakna dengan keterlambatan penderita kanker payudara dalam melakukan pemeriksaan awal kepelayanan kesehatan yaitu tingkat pendidikan, pengetahuan, media massa, keterjangkauan biaya, dukungan suami, dan SADARI. SADARI kanker sangat penting dianjurkan kepada masyarakat khususnya pada perempuan dari usia pertama kali menstruasi sampai usia monoupouse, karena pemeriksaan ini dilakukan sendiri tanpa bantuan dari orang lain. (Wahyuni, 2015)

Peneliti telah melakukan wawancara terhadap 15 wanita usia subur (WUS), didapatkan hasil bahwa wanita usia subur di desa Resun tidak mengetahui, tidak pernah mendengar penyakit dan penyebab dari kanker payudara, belum mengerti cara memeriksakan payudara sendiri, serta pengetahuan wanita usia subur di desa Resun tentang SADARI sangat mempengaruhi sikap mereka dalam melakukan SADARI untuk mendeteksi dini ada atau tidak gejalan kanker payudara.

Berdasarkan uraian yang telah 
peneliti paparkan, Hal tersebut menjadi latarbelakang yang kuat bagi peneliti untuk melakukan sebuah penelitian tentang kemampuan wanita usia subur dalam melakukan tindakan sadari dalam mengetahui penyakit kanker payudara, karena dengan memberikan pengetahuan melalui pendidikan kepada perempuan khususnya kepada wanita usia subur tentang SADARI kanker payudara hal tersebut berarti merupakan suatu benteng dalam mengatasi terjadiya kanker payudara terhadap perempuan dan mengurangi adanya penyakit kanker payudara dan korban jiwa.

\section{METODE}

Metode yang digunakan pada penelitian ini adalah penelitian pre experiment design. Jenis yang digunakan adalah One Group Pretest Postest. Penelitian ini bertujuan untuk mengetahui apakah terdapat pengaruh kemampuan SADARI sebelum dan sesudah dilakukan pendidikan kesehatan. Penelitiian ini dilakukan di Desa Resun Kecamatan Lingga Utara, Kabupaten Lingga, Provinsi Kepulauan Riau. Penelitian ini dilaksanakan pada Januari - Februari 2020.

Populasi dalam penelitian ini adalah seluruh wanita usia subur di Desa Resun. Tekhnik sampling yang digunakan dalam penelitian ini adalah purposive sampling, Pada penelitian ini sampel diambil dari wanita usia subur di desa Resun Lingga Utara yang harus memenuhi kriteria inklusi dan eksklusi, dimana kriteria tersebut menentukan dapat dan tidaknya sampel tersebut digunakan. Besarnya sampel dalam penelitian ini adalah 26 wanita usia subur (WUS). Sampel dalam penelitian ini adalah seluruh wanita usia subur yang ada di Desa Resun Lingga Utara.

Analisis data dilakukan untuk mengetahui pengaruh pendidikan kesehatan dengan metode demonstrasi
SADARI dengan kemampuan WUS melakukan SADARI. Untuk melihat pengaruh antara dua variabel dilakukan uji Willcoxon Matched Paired Test dengan menggunakan perangkat lunak komputer dengan derajat kepercayaan 95\%. Jika uji statistik menunjukkan nilai $p$ value $\leq 0,05$ maka terdapat pengaruh antara pendidikan kesehatan dengan metode demonstrasi SADARI dengan kemampuan SADARI. Sebaliknya jika nilai $\mathrm{p}>0,05$ maka tidak terdapat pengaruh yang bermakna.

\section{HASIL}

\section{Analisis Univariat}

Karakteristik Responden

Tabel 1 Karakteristik Responden di Desa Resun Lingga Utara tahun 2020

\begin{tabular}{|c|c|c|}
\hline Karakteristik & Jumlah & Persentase \\
\hline $\begin{array}{l}\text { Usia } \\
20-25 \\
26-35 \\
36-45 \\
\text { Total }\end{array}$ & $\begin{array}{l}4 \\
12 \\
10 \\
26\end{array}$ & $\begin{array}{l}15,38 \\
46,15 \\
38,47 \\
100\end{array}$ \\
\hline $\begin{array}{l}\text { Pendidikan } \\
\text { SD } \\
\text { SMP } \\
\text { SMA } \\
\text { Sarjana } \\
\text { Total } \\
\end{array}$ & $\begin{array}{l}2 \\
8 \\
12 \\
4 \\
26\end{array}$ & $\begin{array}{l}7,7 \\
30,8 \\
46,2 \\
15,4 \\
100\end{array}$ \\
\hline $\begin{array}{l}\text { Pekerjaan } \\
\text { IRT } \\
\text { Buruh } \\
\text { Petani } \\
\text { Swasta } \\
\text { PNS } \\
\text { Total } \\
\end{array}$ & $\begin{array}{l}9 \\
7 \\
3 \\
6 \\
1 \\
26\end{array}$ & $\begin{array}{l}36,4 \\
26,9 \\
11,5 \\
23,1 \\
3,8 \\
100\end{array}$ \\
\hline $\begin{array}{l}\text { Jenis KB } \\
\text { Tidak KB } \\
\text { Implan } \\
\text { Pil } \\
\text { Suntik KB } \\
\text { Total }\end{array}$ & $\begin{array}{l}3 \\
5 \\
4 \\
14 \\
26\end{array}$ & $\begin{array}{l}11,5 \\
19,23 \\
15,38 \\
53,84 \\
100\end{array}$ \\
\hline
\end{tabular}

Sumber: Data 2020

Berdasarkan tabel 1 diketahui bahwa umur responden penelitian di Desa Resun sebagian besar berada pada kisaran umur 26-35 tahun sebanyak 12 orang $(46,15 \%)$. Hasil penelitian menunjukkan bahwa dari 26 responden yang diteliti, tingkat pendidikan SMA lebih banyak dibandingkan tingkat pendidikan lain 
yaitu sebanyak 12 orang (46,2\%). Karakteristik responden berdasarkan pekerjaan pada penelitian ini sebangian besar responden sebagai IRT yaitu sebanyak 9 orang $(36,4 \%)$. Karakteristik responden berdasarkan jenis kontrasepsi menunjukkan bahwa sebagian besar responden menggunakan suntik KB sebanyak 14 orang $(53,84 \%)$.

\section{Kemampuan Mempraktikan SADARI}

Kemampuan mempraktikan SADARI diukur dua kali yaitu sebelum responden diberikan Pendidikan Kesehatan dan bagaimana bagaimana cara mempraktikan Sadari (pretest) dan sesudah (postest).

Hasil penelitian kemampuan mempraktikkan SADARI sebelum dan sesudah dilakukan pendidikan kesehatan dapat dilihat pada tabel

Tabel 2 Kemampuan WUS dalam Melakukan SADARI Sebelum Dilakukan Pendidikan Kesehatan

\begin{tabular}{ccc}
\hline Kemampuan & Jumlah & Persentase \\
\hline Kurang & 18 & 69,2 \\
Cukup & 8 & 30,8 \\
Baik & 0 & 0 \\
\hline
\end{tabular}

Total

$$
26
$$$$
100
$$

Berdasarkan tabel (2) di atas diketahui sebelum diberikan pendidikan kesehatan sebagian besar responden memiliki kemampuan pada kategori kurang yaitu sebesar 18 orang $(69,2 \%)$, dan responden memiliki kemampuan cukup yaitu sebesar 8 orang $(30,85 \%)$.

Tabel 3 Kemampuan WUS dalam Melakukan SADARI Sebelum Dilakukan Pendidikan Kesehatan

\begin{tabular}{ccc}
\hline Kemampuan & Jumlah & Persentase \\
\hline Kurang & 0 & 0 \\
Cukup & 5 & 19,2 \\
Baik & 21 & 80,8 \\
Total & 26 & 100 \\
\hline
\end{tabular}

Berdasarkan tabel 3 diketahui setelah diberikan pendidikan kesehatan sebagian besar responden memiliki kemampuan pada kategori baik yaitu sebesar 21 orang $(80,8 \%)$, sedangkan responden memiliki kemampuan cukup yaitu sebesar 5 orang $(19,2 \%)$ dan tidak ada satupun responden yang memiliki kemampuan kurang.

\section{Analisa Bivariat}

Hasil analisis data dengan uji Wilcoxon Matched paired Test dapat dilihat pada tabel dibawah ini :

Tabel 4 Pengaruh Pendidikan Kesehatan Dengan Metode Demonstrasi Terhadap Kemampuan SADARI Pada WUS Di Desa Resun Lingga Utara Tahun 2020

\begin{tabular}{llcccc}
\hline & $\mathbf{N}$ & $\begin{array}{c}\text { Mean } \\
\text { Rank }\end{array}$ & $\begin{array}{c}\text { Sum of } \\
\text { Ranks }\end{array}$ & Asymp.Sig \\
\hline $\begin{array}{l}\text { Kemampuan Post } \\
\text { Test - }\end{array}$ & $\begin{array}{l}\text { Negative } \\
\text { Ranks }\end{array}$ & $0^{\mathrm{a}}$ &, 00 &, 00 & 0,000 \\
$\begin{array}{l}\text { Kemampuan Pre } \\
\text { Test }\end{array}$ & $\begin{array}{l}\text { Positive } \\
\text { Ranks }\end{array}$ & $26^{\mathrm{b}}$ & 13,50 & 351,00 & \\
& $\begin{array}{l}\text { Ties } \\
\text { Total }\end{array}$ & $0^{\mathrm{c}}$ & & & \\
& 26 & & & \\
\hline
\end{tabular}


Berdasarkan tabel 4 diketahui hasil analisis data dengan uji Wilcoxon Matched Paired test menunjukkan nilai Asymp.Sig sebesar 0,000 $(<0,05)$ maka disimpulkan terdapat pengaruh yang signifikan antara pendidikan kesehatan dengan metode demonstrasi terhadap kemampuan mempraktikan SADARI antara pretest dan postest.

\section{PEMBAHASAN}

Berdasarkan hasil analisis data dengan uji Wilcoxon Matched Paired test menunjukkan nilai Asymp.Sig sebesar $\quad 0,000 \quad(<0,05) \quad$ maka disimpulkan terdapat pengaruh yang signifikan antara pendidikan kesehatan dengan metode demonstrasi terhadap kemampuan mempraktikan SADARI antara sebelum dan sesudah diberikan pendidikan kesehatan.

Dari hasil penelitian diketahui sebelum diberikan pendidikan kesehatan sebagian besar responden memiliki kemampuan pada kategori kurang yaitu sebesar 18 orang $(69,2 \%)$, dan setelah diberikan pendidikan kesehatan sebagian besar responden memiliki kemampuan pada kategori baik yaitu sebesar 21 orang $(80,8 \%)$.

Postest dilakukan 10 hari dari pretest yaitu pada tanggal 15 Februari 2020, hasil dari penelitian didapatkan hasil Postest lebih baik dari pada hasil pretest, hal ini disebabkan karena adanya suatu perlakuan yaitu sebelum Postest responden diberikan pelatihan cara melakukan SADARI terlebih dahulu. Menurut asumsi peneliti sebelumnya belum pernah mendapatkan pedidikan kesehatan tentang pemeriksaan SADARI, hal ini menyebabkan WUS di desa Resun lingga Utara kurang pengetahuan tentang SADARI.

Hal ini sesuai dengan teori bahwa seseorang setelah mengalami stimulus atau obyek kesehatan, kemudian mengadakan penelitian atau pendapat terhadap yang diketahui proses selanjutnya diharapkan dapat melaksanakan atau mempraktikan apa yang diketahui dan disikapinya (Notoadmojo, Metodelogi Kesehatan, 2012)Pengetahuan adalah hasil dari tahu, dan ini terjadi setelah seseorang melakukan penginderaan terhadap suatu objek tertentu. Penginderaan terjadi melalui panca indera manusia, yakni melalui mata dan telinga. Ada 6 tingkatan pengetahuan yang tercakup dalam ranah kognitif mempunyai 6 tingkatan yaitu : Tahu (know), Memahami (comprehension), Aplikasi (application), Analisis, Sintesis dan Evaluasi (Notoadmojo, 2016)

Tujuan yang ingin dicapai dalam melakukan SADARI adalah meningkatnya kemampuan responden dalam melakukan SADARI. Hal ini sesuai dengan pendapat (Moekijat, 2003) tujuan umum dalam pelatihan adalah untuk mengembangkan keahlian dan pengetahuan.

Pada penelitian ini didapatkan hasil bahwa kemampuan mempraktikan SADARI pada responden yang sudah diberikan pelatihan SADARI lebih baik, hal ini sesuai dengan teori yang mengatakan bahwa keberhasilan pelatihan dipengaruhi oleh beberapa hal antara lain: usia, tingkat pendidikan, dan tingkat pekerjaan, adat istiadat, kepercayaan masyarakat dan ketersediaan waktu di masyarakat (Moekijat, 2003). Menurut (Notoadmojo, 2016)praktik memiliki tingkatantingkatan sebagai berikut: persepsi yaitu responden mengenal dan memilih berbagai obyek yang berhubungan dengan tindakan yang akan diambil. Selanjutnya responden melakukan sesuatu secara urut dan benar sesuai dengan contoh. Mekanisme yaitu responden melakukan sesuatu dengan benar sehingga secara otomatis 
menganggap hal tersebut sebagai suatu kebiasaan. Adopsi yaitu praktik yang sudah berkembang dengan baik dimana tindakan telah dimodifikasi tanpa mengurangi kebenaran tindakan sehingga akhirnya responden mampu untuk mempraktikan SADARI.

Selain itu, metode demonstrasi yang digunakan dalam memberikan pelatihan juga mempengaruhi keberhasilan penelitian ini. Metode yang digunakan dalam pelatihan ini adalah metode demonstrasi dan ceramah. Metode ceramah merupakan sebuah bentuk interaksi melalui penerangan dan penuturan lisan dari pendidikan kepada peserta didik. Selain itu ada beberapa hal yang dipertimbangkan dalam memilih metode yaitu jumlah peserta didik. Hal ini sesuai dengan metode ceramah digunakan jika jumlah peserta didik cukup banyak, metode ceramah digunakan jika materi yang diberikan adalah materi baru dan peserta didik mampu menerima informasi melalui kata-kata (Susi Milwati, 2015). Materi yang disampaikan sesuai dengan kebutuhan responden.penyampaian pelatihan menggunakan alat bantu berupa leaflet, power point, audio visual berupa vidio tentang pentingnya diteksi dini kanker payudara dan alat peraga payudara wanita.

Pada penelitian ini, diperoleh data hasil Postest yang rendah yaitu semua responden sebelum diberikan pelatihan SADARI tidak mampu mempraktikan SADARI. Penelitian sebelumnya yang mendukung penelitian ini adalah (Yulianti, 2016) Hubungan Tingkat Pengetahuan Tentang SADARI dengan perilaku SADARI sebagai Diteksi Dini Kanker Payudara pada Mahasiswi D IV Kebidanan FK UNS. Berdasarkan hasil penelitian diatas dapat dibuktikan bahwa hipotesis diterima yaitu terdapat hubungan antara tingkat pengetahuan tentang SADARI dengan perilaku
SADARI yang termasuk dalam perilaku kesehatan, dipengaruhi oleh faktor keturunan dan lingkungan yang bermula dari pemikiran atas dasar pengetahuan hingga pada akhirnya mucul dalam perilaku (Basir, 2015)

Penelitian ini sejalan dengan penelitian yang telah dilakukan oleh (Suparyanto, 2011), yang mengatakan bahwa terdapat pengaruh sebelum dan setelah pendidikan kesehatan terhadap kemampuan siswi dalam melakukan SADARI sebagai upaya pencegahan kanker payudara dimana hasil skor kemampuan melakukan SADARI sebelum diberi pendidikan kesehatan dan demonstrasi lebih rendah secara bermakna dibanding skor setelah diberi pendidikan kesehatan dan demonstrasi meningkat. Penelitian ini juga sejalan dengan penelitian oleh Syaiful \& Aristantia (2016), dan Montessori (2015), bahwa ada pengaruh yang signifikan antara sebelum dan sesudah diberikan pendidikan kesehatan terhadap kemampuan melakukan SADARI.

Menurut asumsi peneliti, pada penelitian ini peningkatan kemampuan melakukan SADARI dipengaruhi oleh minat responden, dimana responden tertarik untuk dapat mendeteksi dini kanker payudara dan mencegah kematian akibat kanker payudara. Hal ini sesuai dengan pendapat Yakout, ElShatbymoursy, (Lubis, 2017) bahwa kesadaran untuk melakukan SADARI penting ditumbuhkan untuk memotivasi seseorang agar secara teratur melakukan SADARI untuk mengidentifikasi secara dini benjolan abnormal pada payudaranya sehingga dapat segera diobati dan menurunkan kematian akibat kanker payudara.

Tingginya minat seseorang terhadap informasi yang sebelumnya mereka belum pernah mendengar dan mendapatkannya maka seseorang akan lebih termotivasi dalam pemberian pendidikan kesehatan. Pendidikan 
kesehatan dengan metode demonstrasi dapat meningkatkan kemampuan pada responden karena metode ini melibatkan seluruh indra untuk menerima informasi yang diberikan secara langsung oleh peneliti tentang pemeriksaan SADARI. Hal ini sesuai dengan pendapat (Aeni, 2018) yaitu semakin banyak panca indra yang digunakan maka akan semakin jelas pula pengertian atau pemahaman yang diperoleh sehingga WUS mampu melakukan praktik SADARI dengan terampil.

Penggunaan metode demonstrasi dapat dilakukan apabila tersedia alat peraga sehingga memudahkan pemahaman, dalam hal ini indra mata memiliki kemampuan $75 \%$ - $87 \%$ untuk dapat menangkap suatu informasi dan disampaikan ke otak. Pendidikan kesehatan dengan metode demonstrasi ini menggunakan alat bantu berupa phantom payudara dan leaflet tentang materi dan gambar sehingga responden mampu melihat kesesuaian antara teori dan kenyataan sehingga dapat melakukan sendiri. Hal ini sesuai dengan pendapat Syarifudin (2009) yang menyatakan bahwa manfaat alat peraga adalah melihat secara nyata inti materi yang disampaikan sehingga memudahkan responden mencerna materi, menghindari kejenuhan atau rasa bosan karena responden bisa melihat gambar dan tulisan. Dari hal tersebut dapat meningkatkan kemampuan responden dalam melakukan praktik SADARI.

\section{KESIMPULAN}

Dalam penelitian terdapat perbedaan pengetahuan pada wanita usia subur yang ada di Desa Resun Kecamatan Lingga setelah diberikan pendidikan kesehatan dengan metode demonstrasi terhadap pemeriksaaan SADARI dengan peningkatan kemampuan re-demonstrasi sebanyak $80,9 \%$. Metode demonstrasi ini dapat digunakan sebagai salah satu metode dalam memberikan pendidikan kesehatan pada masyarakat karena lebih melekat dalam ingatan. Hal ini dilakukan agar wanita usia subur dapat melakukan deteksi dini terhadap payudaranya sehingga dapat mencegah terjadinya kanker payudara.

\section{DAFTAR PUSTAKA}

Aeni, N. Y. (2018). Pengaruh Pendidikan Kesehatan Dengan Media Video Dan Metode Demonstrasi Terhadap Pengetahuan SADARI.Care. jurnal ilmiah kesehatan.

Anggorowati. (2013). Faktor Risiko Kanker Payudara WanitA. Jurnal Kesehatan Masyarakat.

Basir, P. M. (2015). Potensi Yang Hilang Berdasrkan Health Realeted Qualiti of Life Pada Penderita Kanker Payudara.

Dyanti. (2016). Faktor-faktor Keterlambatan Penderita Kanker Payudara dalam Melakukan Pemeriksaan Awal ke Pelayanan Kesehatan.

KEMENKES. (2019). Data Polemik Penduduk.

L, A. (2013). Faktor Risiko Kanker Payudara Wnita. Jurnal Kesehatan Masyarakat, Volume 8 nomor 2 halaman 122.

Lubis. (2017). Pengetahuan Remaja Putri Tentang Pemeriksaan Payudara Sendiri (sadari).

Moekijat. (2003). teori keberhasilan penelitian sedari.

Notoadmojo. (2012). Metodelogi Kesehatan. 
Notoadmojo. (2016). Penarikan Sampling .

Nursalam. (2013). Konsep Penerapan Metodelogi Penelitian.

Riskesdas. (2018). Angka Kanker di indonesia.

Suparyanto. (2011). Wanita Usia Subur (WUS) .

Susi Milwati, S. (2015). Penerapan

Promosi Kesehatan Metode Demonstrasi dan Keterampilan Pemeriksaan Payudara Sendiri Bagi Ibu-ibu PKK DI KOTA MALANG.

Wahyuni. (2015). Hubungan Tingkat Pengetahuan dan Sikap terhadap pelaksanaan sadari pada ibu rumah tangga di kelurahan jati.

Yulianti. (2016). Faktor-faktor Risiko Payudara (Studi Kasus Pada Rumah Sakit ken Saras Semarang. 